\title{
Social Worker Guidance \& Support to Cancer Patients in the USA \& Slovakia
}

M. Harsaniova (Maria Harsaniova)', G. Meuche (Glenn Meuche)²

${ }^{1}$ St. Elizabeth University of Health and Social Sciences, SK

${ }^{2}$ NO Cancer Care, New York City, USA

\section{E-mail address:}

mayaharsaniova77@gmail.com

\section{Reprint address:}

Maria Harsaniova

St. Elisabeth University of Health and Social Sciences

Nam. 1. Maja 1

81000 Bratislava

SK

Source: Clinical Social Work and Health Intervention

Pages: $42-45$

Volume: 9

Issue: 2

\section{Reviewers:}

Pawel S. Czarnecki

Rector of the Warsaw Management University, PL

Michael Costello

University of Scranton School of education, USA

\section{Key words:}

Oncological patient. Social Worker. Holistic approach. Non-profit Organizations. Research.

\section{Publisher:}

International Society of Applied Preventive Medicine i-gap

CSWHI 2018; 9(2): 42 - 45; DOI 10.22359/cswhi_9_2_06 @ 2018 Clinical Social Work and Health Intervention

\section{Abstract:}

The main objective of this research is to highlight the importance of social, psychological, spiritual care to cancer patients, cancer survivors and caregivers provided by Social Workers.

Cancer is a very important issue in our society and statistics of population affected by this illness are constantly growing. According to American Cancer Society (2018) in the USA, there will be an estimated $1,735,350$ new cancer cases and 609,640 cancer deaths. The holistic 
point of view of oncological patients is very important. In the USA, Oncology Social Workers who are a part of a multidisciplinary team provide social, psychological and sometimes spiritual help. In Slovakia non-governmental help is essential. Nevertheless, there is a small amount of help and support that Social Workers provide to cancer patients, survivors, caregivers.

\section{Methods}

The research was conducted by qualitative method. It consisted of observations and interviews with Oncology Social Workers in the USA and Social Workers in Slovakia. Both results were compared. In the USA the interviews were conducted with Oncology Social Workers in one of the biggest national non-profit organization called CancerCare in New York City. CancerCare provides professional services to help people manage the financial, emotional, spiritual and existential challenges and dimensions of the cancer diagnosis. In Slovakia, Social Workers and one Psychologist were interviewed from the major non-profit organization Liga proti rakovine, which helps patients, survivors and their caregivers.

\section{Results, Discussion and Conclusion}

\section{Questions for Social Workers:}

1. What are the competences of Oncology Social Workers?

2. What kind of help do patients seek the most?

3. What kind of psychological do help patients seek the most?

\section{What are the competencies of Oncology Social Workers?}

In the USA there is crisis intervention, counseling and emotional support for individuals and families. Support groups are very popular where the Social Worker is a leader of the group.

They are part of a multidisciplinary team, as they work with Doctors and Nurses, close to the patients and their families and are part of big hospitals, cancer centers and/or non-profit organizations.

Social Workers also work in palliative care, in hospices, with terminally ill patients and their families. Here they are part of the multidisciplinary team as well. Palliative care and Hospice Social Workers can help to terminally ill and their families cope with the issues that surround death and dying. They can provide a listening ear to those who are dying and provide support to those who are caring for them. SW can help patients and families with concrete issues such as DNRs, medical proxies and funeral arrangements. Then there is navigation, consultation in Social Services such as advocacy, helping with information, resources, financial support, disability pensions or health insurance consultation.

In Slovakia, Oncology Social Workers for patients can be found in the agencies of the General Government (organy statnej spravy) or in non-profit organizations or charities. Here they work in social consultation and very basic emotional counseling/ support. They help and advise with issues of work, financial benefits, sick leave and compensations, disability pension, about Home Health Care Agencies and coordination with the hospices. They work in palliative care as a support to terminally ill patients and their families. 


\section{What kind of help do patients seek the most?}

In the USA patients seek mostly information and advice(s) about the health insurance. Then there is emotional support, issues and communication with the family members, friends or loved ones. They also seek financial help. The importance of communication with a Health Care Team is essential. In Slovakia Oncology patients want to know about issues of work, financial benefits, sick leave and compensations, information about Home Health Care Agencies and coordination with the hospices.

\section{What kind of psychological help patients seek the most?}

In the USA patients seek crisis intervention, emotional help with depression, anxiety, and stress that is caused by the cancer. Patients also seek support to address communication difficulties and issues with the family members, friends or loved ones. Issues surrounding survivorship and resocialization are very important to patients as well. Social Workers can offer comfort to patients who are near the end of life and approaching death and help them as they transition through the stages of dying. (Kubler Ross).

In Slovakia focus is on crisis intervention, individual or family therapy. Work with the family members after the loss of a loved one: survivorship and resocialization. This type of help is still in initial stages. Most of the oncological patients do not want this kind of help, because they think, it is "a weakness" to go into psychotherapy. Education and training is missing, as is Supervision. Psych Oncology is still taboo.

Our conclusion is clear: there are a growing number of cancer patients and their needs are not only biological but also psychological, social, financial or spiritual. In the USA, a big part of this help is provided by Oncology Social Workers. They help as emotional support, social consultant, patient navigator and much more for patients, patients' families and caregivers. They work directly with patients in hospitals, in non-profits organizations and in comprehensive cancer centers or in hospices. In Slovakia we lack Oncology Social Workers and navigation which for most patients' cases is crucial.

\section{Recommendations}

Our recommendation is to have in Slovakia trained Oncology Social Workers in hospitals, more in non-profit organizations, more in government administration and in palliative care.

This way the new diagnosed patients' journey does not have to be confusing. It could start directly in the hospital, where a trained Oncology Social Worker could give information to the patients, depending on their individual needs. This could be called patient navigation which means 'the bridge' between the patient and the complexity of Oncology and managed care.

The bridge would be the Oncology Social Worker. (Kocisova, 2012). An important highlight is psychological help. In Slovakia there are a few Psychologists who help oncological patients. This could change. Social Workers who possess a Master Degree, could continue with their studies and trainings, and become trained and qualified Oncology Social Workers. This could also include psychological help or help to terminally ill patients.

We would like to thank Andrew Chesler LMSW from Cancer Care in New York City, USA and Mgr. Lucia Alaksova from the organization Liga proti rakovine, Slovakia. 


\section{References}

1. AMERICAN CANCER SOCIETY USA life of oncological patients. Social and Po(2018) Cancer Statistics Center. [online]. [citation 2018]. On internet: https://cancerstatisticscenter.cancer.org [5.8.2018].

2. HONZAK IN KOCISOVA A (2012) Social Work and consultancy as a help of quality of litical Analysis 6,2, 97-182 p.

3. KUBLER-ROSS IN BARRACLOUGH J (1994) Cancer and Emotion. Chichester: John Wiley and Sons Ltd, 173s. ISBN 0471937215 . 